\title{
'These people should not rest': mobilities and frictions of the homeless geographies in Athens city centre
}

\section{Panos Bourlessas}

To cite this article: Panos Bourlessas (2018) 'These people should not rest': mobilities and frictions of the homeless geographies in Athens city centre, Mobilities, 13:5, 746-760, DOI: 10.1080/17450101.2018.1464544

To link to this article: https://doi.org/10.1080/17450101.2018.1464544

\section{Published online: 23 May 2018.}

Submit your article to this journal $\pi$

山ll Article views: 377

Q View related articles ¿

View Crossmark data $־$ 


\title{
'These people should not rest': mobilities and frictions of the homeless geographies in Athens city centre
}

\author{
Panos Bourlessas \\ Social Sciences Unit, Gran Sasso Science Institute, L'Aquila, Italy
}

\begin{abstract}
The paper relates homelessness to the 'new mobilities paradigm' by highlighting mobility's constitutive character in homeless geographies, and the politics involved in the making of mobile homeless subjectivities in central Athens. Ethnographic material demonstrates that, within the city's institutional and material context, a specific sense of mobility prevails, which may reflect broader mentalities of managing the poor in times of austerity. The case of a night shelter exemplifies how this institutional sense materialises, whereas crucial frictions are involved in the city's homeless geographies. Yet it is the homeless subjects that embody, experience and make these mobilities and frictions meaningful and political.
\end{abstract}

\section{ARTICLE HISTORY}

Received 17 August 2017 Accepted 22 March 2018

\section{KEYWORDS}

Athens; homelessness; mobility; friction; politics; ethnography

\section{Introduction}

Act one: Saturday noon. We are a group of six, and Andreas, a vendor of the Athenian homeless street paper, is ready to move with us through central Athens; and to show us 'his' Athens. He is our guide in one of the Invisible Tours, a mobile practice that, besides being a considerable source of income, is said to give positive visibility to the homeless subjects. The, often imagined as purposeless, homeless mobility is thus challenged through a form of mobility that makes Andreas visible in a specific way: moving with us, the 'common' people, throughout'his own city', a sense of belonging and normality is performed for the homeless. Indeed, he almost looks like us while we are walking all together. Nevertheless, our route with Andreas is neither random nor that 'common'; instead, it is shaped around very specific spots of the city, connecting them with each other, stop after stop: homeless hostels, day centres, soup runs, the municipal homeless shelter - everything within reach from one another.

Act two: Saturday afternoon. The tour is over and Andreas is now fixed at his post, not away from where he was moving with us earlier; standing here, he is selling the magazine for a few more hours. Not only is he fixed though. He is also wearing the street paper's red jacket, highly recognisable amongst Athenians today; without it he is not allowed to sell his copies. The moment he decides to move from there, he will have to take it off again (as he had to do during our Invisible Tour). The materiality of the jacket hence performs certain spatial associations of mobility and fixity, which affect Andreas' subjectivity. Wearing the jacket relates to fixity, selling the magazine and being visible as a stigmatised 'homeless' - in 'his' place. Not wearing it relates to mobility, moving with us through 'his' city and finally ridding himself of the stigma - almost like being 'normal' again. Experienced and signified, this mobility-fixity interplay has a dividing effect on Andreas; as if the 'fixed Andreas', with the red jacket, is 
different from the 'mobile Andreas', without the red jacket. And, being aware of the stigma performed by the association between fixity and his jacket, he tries to break this association; making the jacket mobile finally, he hopes to de-stigmatise it:

I move to the café [to take a break from selling the magazine] leaving the red jacket on so that it (the jacket) tells [the people there] that it's me again! That I am not different from the person standing there (himself selling the magazine), it is always me. The man to whom you waved 'good morning' a few minutes ago is me. Wearing the jacket does not change my soul or my way of thinking.

These two opening Acts give a grounded example of how meaningful, complex and interrelated mobility and fixity, both as notions and as practices, are for homeless subjects and their geographies. Bringing ethnographic evidence from Athens, Greece, this article explores the homeless mobilities generated by the spots of the Invisible Tour in Act one above: homeless hostels, shelters and day centres comprise the city's 'machinic archipelago', which is 'machinic' in a sense that the places that constitute it, like parts of a metaphorical spatial mechanism, generate multiple forms of mobility.

Relating homelessness explicitly to the'new mobilities paradigm' (Hannam, Sheller, and Urry 2006), and expanding the discussion in this journal (Hall and Smith 2013; Smith and Hall 2016), the article shows how mobility is constitutive of and constituted by the homeless subjects and the spaces of their geographies, and highlights the politics involved in the making of mobile homeless subjectivities in Athens. Within the institutional and material context set by the machinic archipelago, specific forms of mobility and friction matter for the everyday lives of the homeless. Specifically, the case of a night shelter illuminates how the institutional sense of mobility is materialised, and how a critical friction is performed. At the same time, and as Andreas' example has partly shown, homeless subjects embody, experience and make this mobility meaningful while shaping the city's homeless geographies as 'drifters'. I argue that the making of these drifters as mobile subjects is highly political. And with this ethnographic study I aim at locating homelessness within wider social dynamics, such as institutional discourses and new ways of managing the poor, rather than presenting it as an isolated construct (Farrugia and Gerrard 2015).

The paper is organised as follows: It begins with insights from mobility studies, which become the theoretical basis for the homeless mobilities to be described later. Then comes a brief synthesis of literature on the mobility of homeless people. After the methodology, the empirical section begins with a description of the 'machinic archipelago' of central Athens and the institutional sense of mobility articulated through it, attempting to develop a linkage to specific ways of managing the poor in Athens. Then it is time for the main case study: the night shelter materialises the institutional sense of mobility as a practiced 'forced mobility'. We see how this mobility produces the subjectivity of 'the drifter', which becomes meaningful for the homeless through various relations and practices that involve affect, the materiality of their bodies and everyday negotiations. Lastly, two empirical examples illustrate how various frictions relate to homeless mobilities, and thus contribute to the production of homeless geographies. The article concludes with some general remarks, calling to consider relationally mobility's role in the making of marginal subjectivities and social marginality more generally, especially in contexts where new poverty managements may roll out.

\section{Gone mobile}

In their account, Sheller and Urry $(2006,209)$ note that the claim of the'new mobilities paradigm' is'not simply an assertion of the novelty of mobility in the world today [but] rather part of a broader theoretical project aimed at going beyond the imagery of "terrains" as spatially fixed geographical containers for social processes'. To paraphrase this quotation, locating homelessness explicitly within this paradigm would not simply be an assertion of the'novelty' of homeless mobility. The homeless have always been imagined as on the move; if rootedness is a major characteristic of 'home' (Somerville 1992), then anyone defined by the absence of home is understood as rootless and therefore mobile. Instead, this paper extends beyond abstracted imageries of homeless mobilities to understand these mobilities as social processes constitutive of the homeless experience, processes which are also political. 
Cresswell's $(2006,2010)$ interpretation becomes the starting point here: mobility is not about abstract movement. Instead, it is considered a 'necessary social production' $(2006,22)$ that crucially shapes the modern world. It is practiced, meaningful, political. Mobility then is about becoming; a becoming that entails power relations and generates social difference. In this vein, Söderström et al. (2013) propose the concept of 'critical mobilities' in order to highlight how mobility is contested, constitutive of society, part of social processes and always in interaction with the immobile. Indeed, within the'new mobilities paradigm', immobility (or fixity, or stillness, or'moorings') does matter (Hannam, Sheller, and Urry 2006); the ever-increasing and complicated movement in today's societies would not be possible without the fixity of specific locations that produce the 'structural or infrastructural contexts for the practicing of mobility' (Cresswell and Merriman 2011, 7).

Moreover, if mobility is not to be seen as movement abstracted from social meanings, then, as every social process, it becomes constitutive of subjectivities too. Through their movement, human bodies influence each other and eventually 'map subjects' on space (Pile and Thrift 1995). The ways, causes, places and trajectories of moving shape performances that ascribe meaning to the subjectivities in unequal, hierarchical ways: for 'movements are the product and also the producer of our social position' (Cresswell 2006, 109; see also Cresswell and Merriman 2011). Different mobilities result in different mobile subjectivities, which find themselves in a 'differential movement' (Simpson 2017, 4). Spatial movement positions and re-positions us socially. For instance, Adey et al. $(2012,178)$ use the figure of the 'passenger' in order to show how this subjectivity is made through the mobile body and the material assemblages surrounding it, a subjectivity that is 'politicized, socialized, technologized and en-cultured in a variety of different ways'. Other examples of mobile subjectivities are: the commuter (Edensor 2011); the tourist (Crang 2011); and the, most relevant for this article, vagrant/vagabond, moving continuously and aimlessly (Cresswell 2011).

To proceed, within the 'critical mobilities' fashion, it is useful to consider Cresswell's (2010) elements of a 'politics of mobility' aiming at a critical empirical investigation of the mobilities involved in the homeless geographies of central Athens. For the purpose and economy of this paper, specific elements receive attention: the reasons for being mobile, the way it feels and the frictions involved. The following part presents work that directly addresses the mobility of homeless people.

\section{Homeless mobilities}

Mattresses, blankets, chairs, cartons, a comb: such visible traces of private fixity influence common imaginations of homeless mobility. We pass by and take a quick (sometimes slightly guilty) glance at these objects while walking in the city. Perhaps we may slow down a bit, even stop, and look at this stuff when the owner is not there; this materiality of sleeping rough is the marker of one's territory (Wardhaugh 1996). But where is the possessor of this territory? This is one important moment, I think, that the homeless can be commonly understood as mobile: through her/his absence, which is given away by the fixity of things visible to the public eye. If not there, s/he has to be mobile. Above all, though, it is the homeless her/himself who produces common understandings and imageries of homeless mobility: by pushing a shopping trolley in the street, for example, a homeless person deprives the trolley's shopping dimension and performs an emblematic mobile figure.

As matter moving around, the homeless body carries along a very specific signification making it visible to 'common' society. This visibility (as that of the possessor's absence) is crucial: according to Kawash (1998), by being constantly mobile - and inevitably visible, we may add - the homeless body marks the distinction between 'the homeless' and 'the public'; and Cloke, Milbourne and Widdowfield $(2003,23)$ note that 'where the mobility of homelessness becomes visible to the public gaze [...] it is more likely to be 'inappropriate' and thus serve as a signifier of the absence of responsibility and rootedness'. Mobility then is certainly a way the homeless are 'othered' (Wolch, Rahimian, and Koegel 1993; May 2000). However, homeless mobility should not be reduced to a sole line of division; rather it should be considered a meaningful social production that is constitutive of these people's lives and 
subjectivities - the drawing of this line. For '[mobility] alone [...] does not automatically mark out an outsider' (Cloke, Milbourne, and Widdowfield 2003, 23) but is part of specific practices and values.

Lancione suggests that 'homelessness should just become synonymous with "continuous displacement" or a form of it' $(2016,172)$. Indeed, however implicit in many studies, homeless mobility can take a multiplicity of forms, with displacement being its most extreme one, yet not rare. Either explicit or implicit, there is a continuous interplay between voluntary and involuntary forces behind homeless mobility. The former may relate to negotiating the homeless condition (Jackson 2012) and the latter to ways of managing the poor (DeVerteuil 2003); the voluntary/involuntary binary should be constantly questioned as unstable though. This interplay is critically enhanced with the homeless' tactics, either responding to involuntary mobility or rendering mobility itself a tactic, blurring the boundaries between the forces. The following literature review takes into account this interplay and shows the centrality and complexity of mobility in the homeless lives, at various levels and with ambiguous effects.

At the institutional level, DeVerteuil (2003) highlights the interaction between homeless mobility and the broader institutional settings that define it. His critique emphasises the ways the'new poverty management' results in an institutionalised cycling of homeless people, particularly single women, who may move from one structure to the other. Institutional settings largely affect the mobility of these women: their patterns accordingly vary from stable to unstable, and from dependent on to independent from formal structures. For some research participants, being mobile means coping with difficult situations. Similarly, within the limitations posed by institutional contexts, Jocoy and Del Casino (2010) suggest that sociocultural discourses matter too for homeless mobility; for instance, shelter regulations (such as time schedules) that increase movement reflect broader cultural norms. Relating homeless mobility with social marginality, the Authors consider the homeless'not as abstract objects but as active agents negotiating their social and spatial exclusion' $(2010,1944)$ : their travelling involves both places of inclusion and exclusion, depends on material aspects (e.g. car-ownership or public transportation), and challenges conventional, normative binaries that see the mobile as powerful and the immobile as powerless. The work of Wolch and Rowe (1992) in two Los Angeles communities reveals the role of social networks in the daily paths of the homeless. The lack of spatial fixity may result in a 'time-space discontinuity' for the homeless; consequently, their daily paths include alternative social networks so that a compensating sense of 'time-space continuity' is achieved. Moreover, mobility heavily depends on what the Authors name 'locale', namely the 'environmental features, social institutions, and individuals and activities that are present in time-space' $(1992,116)$; service facilities and philosophies shape the locale and therefore homeless mobility.

Beyond the strictly institutional, there are important experience-related aspects of homeless mobility, as 'the experience of homelessness cannot be considered apart from the experience of movement' (May 2000, 737). May (2000) relates mobility with the sense of 'home as place' and, focusing on single homeless men, identifies four types of narratives: first, of (dis)placement, including a 'hollowed-out' sense of place, feelings of isolation and disorientation; second, of homesickness, in which the home as place is constantly searched for; third, of spectral geographies, consisting of spaces that have been meaningful in the past, where the homeless return; and fourth, of the new nomads, continuously searching to (re)establish a sense of home throughout various places. Jackson's (2012) research with young homeless people in London provides evidence of the multiple nuances of mobile lives. Entangled in power geometries, mobility becomes an everyday tactic or important survival resource. Mobility may mean loss (of home or any place that feels alike) or can function as a managing strategy. Taking into account the various (both formal and informal) kinds of surveillance, Jackson argues that the experience of young homeless Londoners highlights that 'fixity is not always mobility's opposite, [but] rather some people become fixed in mobility' (2012, 16, original emphasis).

Last but not least, in this journal, the contributions of Hall and Smith (2013), and Smith and Hall (2016) expand the scopes of the overall debate: focusing on outreach work in Cardiff, Wales, as an important pedestrian practice, their ethnographic accounts offer critical insights on the street-level politics and the subjectivities in the making. Specifically, outreach workers and homeless people are involved in complex pedestrian dynamics of mobility and stillness, with the former looking for the latter and the 
latter looking for social services. Against the background of a visitors-and-consumers attracting city, these practices become ideologically loaded by subjectifying the homeless as third-class citizens (Hall and Smith 2013). In their more recent article, the Authors draw on interactionism in order to show how the delivering of care through pedestrian practices of outreach workers'not only traverses but produces the contours of the landscape, territory and consequent urban politics in which outreach workers move and are entangled' (Smith and Hall 2016, 504). Their evidence adds a further subjectivity in the mobility paradigm, 'the searcher', and calls for more and more attention to'pedestrian circulations [...] that produce winners and losers' (Smith and Hall 2016, 505).

It is to this latter call that my contribution responds. Yet it does so by focusing more on the 'losers' than the 'winners'; and by relating homelessness directly to mobility studies and not indirectly, as Smith and Hall admit for their own work (2016). If the searcher is only one side of the homelessness-related subjectivities shaped by pedestrian practices, this article shows how another subjectivity, 'the drifter', may be made and embodied by mobile homeless people. Furthermore, the overall discussion presented so far focuses exclusively on homeless mobility within the Anglophone world. Los Angeles. Cardiff. Long Beach. London. The south coast of England. Athens here may bring to the fore the role of places and contexts beyond that world; where socio-economic situation now changes so rapidly that the poor and the homeless cannot be that easily 'othered' any more (Kaika 2012); and where landscapes of homelessness are being dynamically shaped and are, above all, contested (Arapoglou and Gounis 2017). The following section describes the methodology used for the paper's empirics.

\section{Methodology}

The role of ethnographic research in mobility studies has been stressed elsewhere (Sheller and Urry 2006; Cresswell 2012). Empirical evidence utilised here comes from a six-month field research (November 2016-June 2017) on the geographies of homelessness in Athens' city centre. Core fieldwork consists of participant observation through daily participation as a volunteer at a homeless night shelter and a homeless day centre in the central municipality, as well as interviews. Further participant observation was conducted during outreach actions run by the Solidarity Centre of the Athens Municipality and two NGOs specialized in outreach work for homeless. Additional fieldwork was carried out in two central homeless hostels.

In total, twenty-eight semi-structured interviews (lasting from 40 min to two and half hours) were conducted with homeless people from different categories: night shelter users and hostel residents; rough sleepers; people hosted by friends or relatives; and vendors of the homeless street paper. Material for this article stems from interviews with fifteen participants: twelve men and three women, including thirteen Greek, one Pakistani and one Moroccan, with ages ranging from 45 to 71 years old. Extensive field notes were made during and after participant observation, the latter including as well walking, using public transportation or waiting with research companions. Fieldwork also included interviews with paid staff, directors of social services and NGOs, social workers, volunteers, and activists related to homelessness. The paper's core, which follows, can be divided into two general parts: about mobility (the'machinic archipelago', and the case study of the night shelter) and about friction (car im/mobilities, and the night shelter's entrance).

\section{The 'Machinic Archipelago' of Athens city centre and its sense of mobility}

The stops made during the introduction's Invisible Tours are critical for this paper's geographies: homeless hostels, day centres, soup runs, the municipal homeless shelter. The metaphor of archipelago to describe the distribution of services for the homeless is not new. Gowan (2010) talks about the 'homeless archipelago' in her ethnography with single homeless men in Los Angeles. Similarly, in his Foucauldian analysis of the governance of homelessness, Arapoglou uses the term 'welfare archipelago' to describe the 'islands of state power and informal control' $(2004,676)$ in central Athens. Indeed, archipelago seems to be a powerful metaphor: on the one hand, it gives a strong sense of the geographical dimensions 
of service provision, such as concentration and distribution; on the other, it stresses the critical role of specific places as constitutive nodes. Yet, homeless archipelagos are not static; their geographies are created through movement - not only of human bodies that may depend on welfare, but also of foodstuff, material objects as well as discourses of charity, policies and volunteer ethos.

This idea of movement (mostly as circulation of the humans involved) regarding homeless provision has been overt in the use of the word 'circuit' by some scholars (Wardhaugh 1996; May 2000; Jackson 2012). Amin and Thrift (2002) propose their famous understanding of the city as a 'mechanosphere', stressing the importance of systems and connections between subjects and objects, where movement is vital. Focusing on this last element, I hereby propose the metaphor'machinic archipelago' in order to understand the role of mobility in the homeless geographies of Athens: geographies shaped through various, more or less institutional places, and through continuous and various mobilities influenced by these places and developed in their in-between space. In the machinic archipelago, places and mobility are in constant interrelation: the former shape the material context for the latter. Or, in the words of Doughty and Murray $(2016,312)$, the machinic archipelago '[constitutes] the "conditions of possibility" for the development of certain types of mobile practices'. Like in any mechanism, places function as nodes that absorb and, at the same time, generate mobility. For instance, during the extreme weather conditions of December 2016, the City of Athens Homeless Shelter orchestrated a massive circulation of blankets, mattresses, food portions, medicines, clothes, and outreach teams and 'experts' that reached other nodes of the machinic archipelago and the streets of Athens. On a more regular basis, the type and quality of provision, specific regulations and timetables of the nodes are pivotal elements in the mobility of people involved in the archipelago. Of course, the use of words such as 'mechanism' or 'machinic' does not intend to de-humanise the archipelago and its geographies. Rather, 'machinic' aspires to give an appropriate sense of movement, central to this article. This dynamic network of services is seen as the institutional and material context in which mobile homeless subjectivities are made along with their geographies.

Forming our understandings of mobility discursively, institutions are critical to the practice of mobility (Doughty and Murray 2016). For the case of Athens, in their recent overview, Arapoglou and Gounis (2017) pay particular attention to the mentalities that drive the emergent management of the city's poor and homeless, and position subjects accordingly. As an ingredient of these mentalities, throughout the machinic archipelago of central Athens there exists a specific institutional 'sense of mobility': that of individual mobilisation. According to the official discourse, homeless people ought to be constantly mobilised. This sense reflects workfarist ideas of self-responsibilisation, expected to make individuals move out of homelessness (Whiteford 2010). Physical mobility and personal mobilisation are interrelated. But this sense of mobility concerns a specific scale: that of the body - or even parts of it. 'These people should not rest, they should get mobilised [...] to stand on their own legs', the head of the City of Athens Homeless Shelter said during a conference on tackling homelessness at the municipal level (December 16, 2016). The bodily movement of the homeless needs regulation and is desired as specific: continuous and tiring. This institutional sense of mobility, however discursive, is strongly material too. The legs are the part of the body that best symbolises personal mobilisation: '[Hostel residents] should get their shoes melted in search for job, every morning', stated the manager of a central hostel (personal communication, February 2, 2017). Through the legs, physical homeless mobility relates to personal mobilisation - a bodily movement that should by no means be pleasurable: standing on one's legs means melting one's shoes.

Yet this official sense of mobility should be seen relationally (see Manderscheid 2014): a complementary 'sense of fixity' seems to corroborate it, this time from the homeless' side. Fixity is signified as negative, undesired for everyday survival. It can result in stigmatisation, attract attention and/or entail dangers: for Hamza' from Pakistan, once a rough sleeper and now a night shelter user, '[being on the street] your first interest is to move away from [the spot], not become fixed [...] because you trigger suspicions.' This sense of fixity is also related to the fear of giving permanence to the homeless condition: '[While sleeping rough] I had to leave Kallithea (a suburb). I had to because I started being fixed there', Demetris said. Hence, being mobile is a way to avoid establishing an undesired fixed street life: 'When 
you stay in one place, people around get to know you [...] I didn't want to become used to this lifestyle', Hamza continued. Besides establishing undesired relationships, fixity may too threaten relationships with people whose tolerance is important for the survival of the homeless. Orestis, a Greek research companion that lives in a makeshift shack in a central neighbourhood, never hangs his clothes outside to avoid the neighbours' suspicions that he is fixed to the location.

If the making of mobility is about'producing and moulding the perceptions, imaginaries and experiences of mobile - or immobile - urban people, and thus involves mechanisms of power' (Jensen 2011, 267), we must consider how the institutional sense of mobility is practiced through the machinic archipelago, aiming to reveal the politics in the making of social difference through mobility. This paper's case study is a night shelter for homeless people. Considering the crucial role 'distinct social spaces' play in the production of mobilities and the 'new forms of social life' that they coordinate (Sheller and Urry 2006, 213), I will attempt to show how this site exemplifies best how the institutional sense of mobility becomes practiced and makes homeless subjects mobile in specific ways.

\section{The night shelter: forced mobility and the subjectivity of the drifter}

The difficult thing is to move your feet out of the mud [...] Waking up, having to leave the place at eight o' clock, looking for a place to eat or have coffee for free, choosing which bench to sit on ... in order to be at five to seven in front of the shelter's door that opens at seven thirty (Manolis, April 4, 2017).

According to the paid staff, besides offering a bed and necessary sanitary facilities, the aim of the night shelter is actually to mobilise the homeless and make them responsible for themselves and effectively deal with their condition. This philosophy complies with the institutional sense of mobility: every morning, all users have to leave the building at 07:30; they can return and reenter between 19:30 and 22:00. From a 'critical geosophy' point of view (Cresswell 2006, 21), the institutional sense of mobility, which relates to personal mobilisation, is materialised as 'forced mobility'; here the homeless are forced to move out, a fact that inevitably results in being (more or less) mobile for at least twelve hours per day. Elsa angrily said: 'I cannot stand like a statue from seven thirty to seven thirty'. After all, statues have no needs to fulfill.

What seems to be desired - and made - in the shelter, is the mobile homeless, who embodies a form of movement that is considered by the personnel positive and necessary for shaping self-responsibility, keeping homeless subjects alarmed and hence resulting in their social reintegration. If we consider 'mobility as part of a governing logic' (Jensen 2011,262), the night shelter's forced mobility is a governing, disciplinary practice coupled with constant uneasiness. Mirroring 'workfarist' approaches to social provision that prevail in Greece, and Southern Europe more generally, during austerity times (Arapoglou and Gounis 2017), forced mobility is expected to result in alertness, as a constant reminder of the homeless situation. In fact, Nikos, once a rough sleeper, described the being-in-the-street as an activating condition: 'In the street you get alerted because you constantly look for a hole to get away through. Because you don't feel safe, you feel the cold, you feel the heat'.

Any form of forced mobility is political though, and the reasons why one moves should be considered to reveal this political (Cresswell 2010). Being excluded from space in general, the homeless are forced to be on the move, something that renders them perhaps powerless (Jocoy and Del Casino 2010). Materialising the institutional sense of mobility in such a way, the night shelter becomes a temporary and paradoxical 'space of exclusion': the very place that accommodates its users at night forces them to be mobile outside of it during the day. The quotation opening this section expresses this paradox. An outward movement is necessary, guided by one's own legs. Again, the legs are the bodily parts par excellence. Individual movement depends on their movement and so they have to be mobile. However, the shelter's regulations and forced mobility make this movement feel difficult for the homeless. The shelter itself is the mud too, stuck on the homeless' feet.

Therefore, forced mobility and its surrounding governing logic may have different results than expected. The homeless who find themselves under this condition seem to perceive themselves mostly 
as drifters rather than mobilised citizens, let alone self-mobilised. What matters here is that mobility is practiced through the human body (Cresswell 2010). The words of Manolis above show importance the - symbolic and material - of the individual's experience, and the role of the body-scale for the homeless mobilities and their politics. The rest of this part utilises ethnographic evidence in order to sketch the subjectivity of 'the drifter' that makes forced mobility meaningful, as experienced by the homeless themselves.

\section{The drifter}

To begin, the shelter's forced mobility produces meaningful subjects through a certain symbolic figure, as perceived by the homeless. Many research participants used the word 'drifter ${ }^{\prime 2}$ to describe their daily being-on-the-move. The word is anything but neutral. The homeless signify the embodiment of the drifter in a very specific way. In Manolis' words, 'becoming a drifter means the end, it is the bottom one can reach. Then you lose any interest to save yourself'. Rather than feeling mobilised, being in a state of forced mobility is often perceived as a passive condition. Time simply passes by for Mimis: 'You simply drift from early morning, to forget, not to think, to make time pass by', whereas Elsa feels like she is wasting her time just 'walking around pointlessly'.

Drifting is practiced as a particular, embodied way of walking. Markos described it as a bodily practice with a strong impact on himself: '[Walking around] you look downwards in order to find some cigarette leftovers, some coins ... You don't raise your head up [...] [At the night shelter] we have learnt to look towards the ground in order to find something'. Looking downwards is socially loaded: like a sort of 'personal gravity', the gaze inevitably pulls downwards the head too. A human figure with the head turned down may be thoughtful, embarrassed, disappointed or desperate - thus loaded negatively. Quite the reverse, to hold one's head, and therefore gaze, high signifies personal strength, self-confidence or pride. Markos perceives himself in a specific way due to his way of drifting, and his words above stress the need to raise one's head up. Similarly, this way of pointless walking relates to perceptions of personal dignity for Hamza:'I don't want to go around all these places [...] I need to preserve my dignity and self-respect.' If subjectivities are spaced (Simpson 2017), then the drifter is a critical product of the forced mobility: a symbolic as well as practiced figure that the homeless subjects embody, a figure that reminds us that the spacing of homeless subjectivities happens also on the move. And the way it feels to be a drifter reveals further aspects of the politics of homeless mobilities.

\section{The drifter and affect}

Cloke, May, and Johnsen (2008) have stressed the affective aspects involved in the several places that make homeless geographies, while for Jensen (2011), affective experiences of mobility should be considered in order to reveal power relations. Beyond the cognitive, being in a state of forced mobility provokes several feelings that add further to the meaning of 'the drifter'. First, it may be felt as inhumane. Youssef, a Moroccan shelter user with physical disabilities, offered a comparison: 'Even a dog has to find a place to rest, cannot wander forever.' For him, the status of the drifter is lower than the one of a dog. Forced mobility may be stressful but can also provoke feelings of a disposable self, as described by Elsa:'In the morning you wake up and feel stressed because you HAVE TO be outside. And it is pointless because you feel thrown away, totally thrown away, because you don't offer anything, neither to yourself nor to anyone else'.

Other users stated that forced mobility makes them lose their mood, 'feel down'. Feelings of shame are involved in Manolis' movements in the city, defining his everyday paths: 'The very first days I was trying to hide even from my own self. I avoided any place where someone could have recognised me'. Yannis narrated how being mobile while not affording the ticket fair becomes shameful:'There was much ticket control those days [...] Perhaps not everyone feels ashamed but I myself in front of 50 people, not having paid the fair ... how embarrassing!' Stressing the affective dimensions of forced mobility not only gives agency back to the homeless subjects but also reveals the 'mundane yet vital sensory, 
feeling capacities that both precede and exceed [...] strategizing and resistance' (Daya and Wilkins 2013, 359). Affect can make homeless agency more complete then. And affect cannot be perceived aside from the materiality of the body.

\section{The drifting body}

The body is inherent in the homeless condition, being the marker between the'public' and its potential usurpers (Kawash 1998). Beyond this basic division, however, the homeless body is made through a material-immaterial interplay that produces certain realities for the homeless. Forced mobility has a considerable effect, especially when intersecting with lines of age and/or physical disabilities. Having to move constantly is tiring, a place for some rest and fixity feel necessary but difficult to find. Maria, who is in her early fifties, described how her bodily movement has now changed to the state of dragging: 'Merry-go-round all day long, I am tired, I've grown old [...] I don't walk any more, I drag myself'. It happened many times during fieldwork that people showed me their swollen or wounded feet as personal evidence of their daily forced mobility. Pointing at her red toe, Elsa once told me, 'This is because of walking. I am limping.' And another time while putting antiseptic on her foot: 'I never had callouses on my feet. These shoes have been split apart'. The bodily effects of mobility shape the subjectivity of the drifter and, therefore, the self.

Not only the body itself and its performances become part of one's self but also, in a phenomenological account, forced mobility is perceived through the body:'I feel a constant exhaustion. All this (being mobile) is absolutely bodily', Elsa said. The material conditions of the drifting body have immaterial consequences in the case of Manolis:'I get EX-HAUST-ED. Bodily tiredness now brings me psychological tiredness'. Preserving one's own dignity is related to whether and how bodily needs are met. Mimis gives a powerful example: 'While on the street you have needs to fulfill. The food you normally eat is not the best and it happens that you urgently need a toilet and don't have access to any. You are obliged to get demeaned!'Thus, forced mobility can largely affect the homeless body both materially and immaterially. If 'to walk is to lack a place' (De Certeau 1984, 103), the drifter's need to walk - or, more generally, to be mobile - represents the absence of a fixed place. To be mobile is to create place on the move through the homeless body. As the physical and psychological conditions of their bodies deteriorate (in a perpetual state of drifting and the impossibility of resting), for instance under a 'forced mobility', the homeless in Athens may become dispossessed even from the 'only place' they have as 'secure' - their own body: a body-place that is made of memories, meanings, bodily needs and affect, moments of uncomfortable stillness, and, finally, purposeful routes throughout the city.

\section{Drifting purposefully}

Notwithstanding the forceful forms of homeless mobility, homeless people play an active role in it through various negotiations. Empowerment through mobility is often explicit:'I create myself my own mobility', Orestis proudly said. Such disruptive discourses of mobility (Doughty and Murray 2016) should be considered within the social and material context of the machinic archipelago. Hamza expressed his need to add a purpose in his moving around: 'I just pass my time by doing something. I don't want to spend my time just walking around and wait until six o' clock to be there.' This 'something' can vary from job searching to socialising. Within the condition of forced mobility then, there exists a'purposeful mobility' that aims to make one's day meaningful in her/his own terms and provide the homeless with feelings of satisfaction, social inclusion, or'normality' - in other words, with forms of empowerment. For example, Arghiris goes to a refugee camp on a daily basis as a volunteer: 'What should I do?' he asked me ironically, 'drift all day long and move from square to square and from bench to bench!?'

The'doing something' discourse seems to interweave with more explicit forms of mobility as a strategy for the drifter; 'being in a state of mobility requires the development of tactics' anyway (Jackson 2012 , 9). Agathi volunteers daily at the National Garden where she takes care of animals. Directing her forced mobility in this way, she turns in into a meaningful tactic that helps her deal with the negative 
aspects of shelter life: 'Why not, otherwise where do I go? [At the Garden] I lose myself, don't think of what happens in [the shelter], have something to do'. Memory is also important; Manolis uses forced mobility in order to pass by the places where he grew up or where his wife had lived. Moreover, going back to his old neighbourhood becomes a tactic that hides the homeless status and obliterates social difference by performing a sense of 'normality':'Nobody knows [in my old neighbourhood] ... (laughing) They think I am still rich and expect me to offer drinks [...] I don't allow voices to pull me downwards'.

Such purposeful mobilities seem to comply well with the institutional sense of mobility as homeless subjects seem indeed to activate themselves. Perhaps though they become active not in the way desired by the official discourse and emergency forms of managing the poor: for example, not being a source of income, volunteering does not open apparent pathways out of homelessness either for Arghiris or for Agathi. But purposeful mobilities are a decisive way for the homeless to regain agency, feel empowered and take control of their own everyday lives, a control that seems to be partially taken by the machinic archipelago. The next, final part brings to the fore the importance and politics of the frictions involved in Athens' homeless mobilities and geographies.

\section{Homeless frictions}

If we turn back to the paper's opening acts, we see mobility practiced and experienced in a productive, meaningful and complex interplay with fixity. Expanding to a third element of the politics of mobility, this part relates the homeless geographies of Athens with mobility research that highlights the importance of the immobile, of fixity, of 'moorings' (Adey 2006; Hannam, Sheller, and Urry 2006; Cresswell 2012). Mobility should always be seen as dependent on, and in relation to, forms, practices and places of immobility. For Söderström et al. (2013), considering the interaction between the mobile and the immobile is essential for a 'critical mobilities' approach, whilst Adey $(2006,87)$ underlines how 'mobility/moorings constitute, and are constituted by, social relations.' This part argues that being mobile as homeless in the machinic archipelago of central Athens involves several practices of stasis that have a significant impact on the homeless subjectivities and further stress the politics of their making as mobile.

Before proceeding with the empirics, it is important to distinguish between two terms here: 'fixity' and 'friction'. Both can be seen as two different sides of what can be called 'stasis'. That is immobility at a conceptual level: the neutral state of being still, outside of any social context - to the extent this is possible. Previously we have seen how important and meaningful the idea of fixity has been in relation to both the sense of mobility (from the institutional side) and the need to be actually mobile (from the homeless' side). Fixity, then, can be considered as a geographical notion that shapes social meaning and hence enables specific practices. Examples of such practices that originate from fixity's negative signification are the night shelter's forced mobility, as well as the frequent purposeful movement of rough sleepers aiming to avoid stigmatisation.

Friction is the second aspect of stasis, or the other side of fixity. Friction is fixity lived: embodied, experienced, contested, and meaningful. During friction, fixity is performed. Most importantly, friction matters because it can be a visible practice, relating the person in friction with the 'outside', which either imposes the friction or can simply observe it - something that makes friction even more political. If it is the 'relational' that matters for the politics of mobility (Adey 2006; see also Manderscheid 2014), then visibility becomes a key actor that renders friction relational: it performs the relationship with the outside and, consequently, performs social difference.

For Yannis, his fixity emphasised his difference from the rest of the people: '[a reason for moving while sleeping rough] was also that I myself was different from passers-by and didn't want them to see me sitting on a bench, immobile, while they were coming from and going to their jobs'. In this case, friction is activated because the contrast between (a negative) fixity and (a positive) movement is visible. This visible contrast may lead someone to perform other, more desired forms of mobility as a way to negotiate friction. Demetris, another vendor of the street paper and former rough sleeper, stressed how important it was for him to achieve being seen by others as mobile in specific terms:'People didn't see me as homeless! They would just see a traveler with his suitcase!' Here, the social difference that 
friction can perform is actively, albeit temporarily, obliterated; put differently, '[mobility] enables the homeless to hide their status for a while' (Jocoy and Del Casino 2010, 1959).

However, there is no clear-cut distinction between the two sides of stasis. They are in constant interrelation and the in-between line is extremely thin and fragile. Fixity always gestates the danger of friction. For some people or groups, the potential friction is negative and hence fixity is avoided. The critical role of friction in the homeless geographies and mobilities is gradually explored in two empirical cases, as follow: living in a car, and the night shelter's entrance. The former illustrates the importance of friction through efforts by the homeless to avoid it; the latter describes a crucial form of friction that the shelter users have to undergo every day.

\section{Car im/mobilities}

... in the middle of the sea with a Nissan Sunny. (Andreas, March 29, 2017)

For some research companions, living in a car has been the first stage of their homeless pathways. Being homeless and im/mobile in a car is an experience in which the relationship between fixity and mobility, and the danger of friction are exemplified. Phoebus spent months in his car before moving to a hostel:'I always had to find a place [to park the car] where I could then move from'. Security can be one reason for moving the car in order to avoid friction; being immobile can entail serious danger and potential harm. Andreas explained:

I was changing position for security reasons, almost every two or three days [...] for my own safety because drunken, thieves and the like frequent such places [where I used to park]. If they notice that you live inside, they knock on the window, pierce the bald tyres.

The most important aspect of car im/mobility though seems to be a certain stigma that can activate friction. As Phoebus' experience shows, this stigma is often countered with actions that aim to distort the impression of visible fixity:

I didn't like people seeing me inside the car, really [...] I was pretending to speak on the phone sometimes, was buying a cheap coffee in order to place the coffee cup on the car [to make it visible], was having a cigarette although I wouldn't smoke normally, [...] doing such things ... opening the window so that the smoke would come out [and be seen] ....

A similar practice can be walking around the area in order not to be seen inside the car all day long. If the homeless mobilities often involve 'tactics of invisibility' (Cloke, Milbourne, and Widdowfield 2003, 30), the above experiences of research participants demonstrate that friction, or the fear of it, may involve 'tactics of distorted visibility'. When visibility cannot be avoided, it needs to be performed in desired terms, at least temporarily.

\section{The night shelter's entrance}

In the homeless geographies of central Athens, the night shelter's entrance could be described as one of what Adey calls 'obligatory points of passage' $(2006,88)$ for some homeless subjects. Entering the building is strictly regulated: names, surnames, day counts and bed numbers of users are written down; the bags are searched for inappropriate items (such as knives, razors, drugs etc.); and the homeless bodies are controlled by the personnel with a metal detector. One person enters each time and when the control is over, the next one enters. The rest just have to wait patiently outside the door - all together. This time-consuming 'rite of entrance' imposes a specific rhythm to the flow of people entering the shelter, and the entrance thus possesses particular dynamics: it performs a powerful friction for the homeless, who find themselves in a 'less comfortable form of stillness' (Cresswell 2012), as described below.

This waiting performs a restrained centripetal momentum for the homeless, pulling their bodies inside but, at the same time, holding them 'fixed' right outside the door. The rite of entrance is highly affective. The opposite forces of the desire and impatience to enter on the one hand (as a result of the forced mobility), and the fixity necessary for the control on the other, make the bodies suspended in an 
uncomfortable stasis, resisting their momentum inwards:'Even if the shelter opened at four, we would be there waiting from three. When it used to open at six, we were there at five. Now [that the opening has been postponed till 19:30] we have to wait till seven thirty', Mimis accepted. Friction regulates the homeless movement at the body level regardless of the urge to enter. Moreover, the entrance's friction is immersed in a peculiar, uncomfortable silence. Only a few jokes or words are heard, sometimes. On the contrary, some minutes later inside the shelter the same people become talkative and interactive both among themselves and with the personnel and volunteers. It seems that friction matters.

Visibility is again critical. In the context of the homeless night shelter, the fact that the people gathered in fixity outside are visible may have an impact upon the individual stigma a homeless person often gets: being fixed altogether while waiting performs an emphasised, collective stigma when seen from passers-by. To avoid friction some may arrive late on purpose, while others remain in the area but are hesitant to stand close to the entrance. For example, Markos tends to postpone this friction:'Before entering, I need to take three strolls around'. Manolis highlighted the friction's affective impact:

[I go] faraway. When I am close [to the shelter] I have a feeling of stress, that time is approaching! If I sit at the coffee place [around the corner] as others do, asking constantly what the time is .... Oh! It is something to seven .... This is sickness, mental sickness!

Another pivotal element of the visibility of friction is the control happening at the entrance. Although the control takes place indoors, the glass door does not hinder the view from the outside. And even if most research companions believe it is necessary, being controlled and visible has a certain impact. When related to the body, the gaze is never neutral but 'charged with feelings, moral judgments and condemnation' (Makrynioti 2004, 33). The following discussion with Manolis is illuminating:

\footnotetext{
Manolis: At some point [the control] becomes demeaning. There should be a sort of neutrality, this humiliation should not be seen from outside. This humiliation not to be seen! It is criminal.

Myself: $\quad$ How does it make you feel?

Manolis: A criminal!

Myself: $\quad$... As if you did something bad?

Manolis: Yes. Although it is right, it is not wrong. But it is a bit ... sheriff-style. And you are being watched! Watched! From people next door and the others waiting.

Myself: $\quad$ Can someone get used to this?

Manolis: No. You get used to it only in a space where you are not visible [...] You don't want to be visible while being controlled.
}

Volunteering at the night shelter, I myself have several times experienced the friction - of course from a completely different position. Although I was allowed to enter the shelter anytime, it was emotionally difficult for me to enter every time I arrived around the opening time, when people were gathered outside: bypassing the rite of entrance would mean to perform, make visible and emphasise the difference between myself and the homeless, with the latter subjected to the friction whereas myself being able to avoid it. And although users would always open space politely for me to pass, I always felt the necessity to hold back my bodily movement in order not to visibly challenge the friction - I had to go (better: stay) with the friction, yet untouched by the stigma. Hence the entrance, along with its friction, has always been a powerful - often uncomfortable but certainly practiced - reminder of my positionality and subjectivity as a researcher.

\section{Concluding relations: homeless subjectivities, mobile politics}

Manderscheid $(2014,192)$ invites us to consider'mobility practices as relational practices'. The homeless mobilities and the geographies they shape in central Athens are indeed practiced and relational. This article has shown how the current making of the contested landscapes of homelessness in Athens (Arapoglou and Gounis 2017) is anything but static and involves the making of mobile subjectivities. The presented homeless mobilities relate the discursive level to the human body or parts of it, the 
institutional framework to its material manifestations, the mobile to the immobile, and abstract senses to the subjects that are forced to embody them. The machinic archipelago of Athens channels the motion and circulation of homeless bodies, as well as involves important moments of, more or less uncomfortable, fixity. An institutional sense of mobility exists that demands the homeless to be self-mobilised as a means to give an (individual) end to homelessness; in the words of Hall and Smith, 'movement is affirmed, is where the action is; stasis is condemned, pathologised' $(2013,276)$. In an emerging workfarist context of managing the poor, self-mobilisation means self-responsibilisation and the scale of the body, and parts of it, are central. Shaping the 'conditions of possibility' for mobility (Doughty and Murray 2016), the night shelter affects the making of mobile homeless subjectivities, and materialises the institutional sense of mobility. The latter is here practiced as 'forced mobility' imposed over the homeless it accommodates every night; they must remain mobile for at least twelve hours every day.

From a critical mobilities perspective, this forced mobility is constantly reshaped and challenged by the homeless who make it meaningful through embodying and negotiating it. Frictions are critical. Living in an im/mobile car entails an undesired visibility that makes regular mobility and 'tactics of distorted visibility' necessary. The night shelter's entrance, with its'rite of entrance', produces an important everyday friction for the homeless subjects who, being fixed and visible, gain a collective stigma while waiting in an uncomfortable form of stillness. Inside, homeless mobility is regulated at the body level through control, whose visibility has affective impacts on the making of homeless subjectivities. Overall, the interplay between mobility and fixity in Athens' homeless geographies includes multiple forms of negotiations that spatially expand beyond institutional reach: from avoiding being seen and stigmatised as 'visible homeless' to tactics of empowerment and 'doing something' for their condition.

It is then important to consider what the institutional sense of mobility can perform in relation to the homeless subjects involved, especially in a geographical context where the rolling-with-neoliberalism poverty management critically reshapes the homeless, amongst other, subjectivities (Arapoglou and Gounis 2017). If the passenger is only one exemplary character in order to understand how mobility contributes to the making of modern subjectivities (Adey et al. 2012), we ought to think about other, not othered, subjectivities that are made through different forms of mobility that are, for instance, forced and depending primarily on one's body. And if with 'a sturdy pair of shoes [we can] see the politics of urban life enacted and experienced' (Smith and Hall 2016, 505), this article's 'drifters' shows us how sturdy their shoes are not, after walking the streets of Athens for hours and hours and hours. The pedestrian practices the 'drifters' embody show how the institutional sense of mobility may produce homeless subjectivities that remind us more of the vagrant/vagabond rather than that of modern active, workfarist and self-responsibilised individuals. Nevertheless, while the vagrant/vagabond necessitated forms of regulations in modern societies (Cresswell 2011), the drifter may be a product of specific regulations within the overall poverty management in Athens.

Can then the forced mobile homeless offer alternatives to the politics of mobility and subjectivity? Yes, I argue. But then, as in the case of the passenger, we are ethically obliged to respect and reveal the drifter's 'radical ambiguity' (Adey et al. 2012, 173), as well as the drifter's radical multiplicity produced along lines of ethnicity, gender, age and/or physical disabilities. Bringing homelessness directly into the 'new mobilities paradigm' does not simply aim at giving agency back to the homeless people by focusing on their mobile patterns and experiences. It also reveals mobility's pivotal role in the production of homeless marginality in broader, contextual social dynamics; homeless drifters in Athens are subjectivities that embody self-responsibilisation but also forms of personal negotiation. In the end, it shows how this mobile agency is highly spatial, relational and political.

\section{Notes}

1. So as to protect the privacy of research participants, names are replaced with pseudonyms.

2. It is worth mentioning that the first research companion who mentioned the word used the English one although our conversation was in Greek. 


\section{Acknowledgments}

A big thank-you to Elisa Bignante, Joseph Patton and, especially, Alberto Vanolo for commenting on this paper's earlier messy drafts, and for encouraging the publication efforts now hidden behind its lines. I am also grateful to the Journal's Editors as well as the two anonymous reviewers for their constructive feedback and guidelines.

\section{Disclosure statement}

No potential conflict of interest was reported by the author.

\section{References}

Adey, Peter. 2006. "If Mobility is Everything Then It is Nothing: Towards a Relational Politics of (Im)mobilities." Mobilities 1 (1): 75-94. doi:10.1080/17450100500489080.

Adey, Peter, David Bissell, Derek McCormack, and Peter Merriman. 2012. "Profiling the Passenger: Mobilities, Identities, Embodiments." Cultural Geographies 19 (2): 169-193. doi:10.1177/1474474011428031.

Amin, Ash, and Nigel Thrift. 2002. Cities: Reimagining the Urban. Cambridge: Polity Press.

Arapoglou, Vassilis P. 2004. "The Governance of Homelessness in Greece: Discourse and Power in the Study of Philanthropic Networks." Urban Studies 41 (3): 621-639. doi:10.1177/0261018304241005.

Arapoglou, Vassilis P., and Kostas Gounis. 2017. Contested Landscapes of Poverty and Homelessness in Southern Europe. Reflections from Athens. Cham: Palgrave Mcmillan.

Cloke, Paul, Jon May, and Sarah Johnsen. 2008. "Performativity and Affect in the Homeless City." Environment and Planning D: Society and Space 26 (2): 241. doi:10.1068/d84j.

Cloke, Paul, Paul Milbourne, and Rebekah Widdowfield. 2003. "The Complex Mobilities of Homeless People in Rural England." Geoforum 34 (1): 21-35.

Crang, Mike. 2011. "Tourist: Moving Places, Becoming Tourist, Becoming Ethnographer." In Geographies of Mobilities: Practices, Spaces, Subjects, edited by Tim Cresswell and Peter Merriman, 205-224. Farnham: Ashgate Publishing.

Cresswell, Tim. 2006. On the Move: Mobility in the Modern Western World. New York, NY: Taylor \& Francis.

Cresswell, Tim. 2010. “Towards a Politics of Mobility." Environment and Planning D: Society and Space 28 (1): 17-31. doi:10.1068/ d11407.

Cresswell, Tim. 2011. "The Vagrant/Vagabond:The Curious Career of a Mobile Subject." In Geographies of Mobilities: Practices, Spaces, Subjects, edited by Tim Cresswell and Peter Merriman, 239-253. Farnham: Ashgate Publishing.

Cresswell, Tim. 2012."Mobilities II: Still." Progress in Human Geography 36 (5): 645-653. doi:10.1177/0309132511423349.

Cresswell, Tim, and Peter Merriman, eds. 2011. Geographies of Mobilities: Practices, Spaces, Subjects. Farnham: Ashgate Publishing.

Daya, Shari, and Nicola Wilkins. 2013. "The Body, the Shelter, and the Shebeen: An Affective Geography of Homelessness in South Africa." Cultural Geographies 20 (3): 357-378. doi:10.1177/1474474012469886.

De Certeau, Michel. 1984. The Practice of Everyday Life. Berkeley: University of California Press.

DeVerteuil, Geoffrey. 2003. "Homeless Mobility, Institutional Settings, and the New Poverty Management." Environment and Planning a 35 (2): 361-379. doi:10.1068/a35205.

Doughty, Karolina, and Lesley Murray. 2016."Discourses of Mobility: Institutions, Everyday Lives and Embodiment." Mobilities 11 (2): 303-322. doi:10.1080/17450101.2014.941257.

Edensor, Tim. 2011. "Commuter: Mobility, Rhythm and Commuting." In Geographies of Mobilities: Practices, Spaces, Subjects, edited by Tim Cresswell and Peter Merriman, 189-204. Farnham: Ashgate Publishing.

Farrugia, David, and Jessica Gerrard. 2015. "Academic Knowledge and Contemporary Poverty: The Politics of Homelessness Research." Sociology 50 (2): 267-284. doi:10.1177/0038038514564436.

Gowan, Teresa. 2010. Hobos, Hustlers, and Backsliders: Homeless in San Francisco. Minneapolis, MN: University of Minnesota Press.

Hall, Tom, and Robin James Smith. 2013. "Stop and Go: A Field Study of Pedestrian Practice, Immobility and Urban Outreach Work." Mobilities 8 (2): 272-292. doi:10.1080/17450101.2012.659470.

Hannam, Kevin, Mimi Sheller, and John Urry. 2006. “Editorial: Mobilities, Immobilities and Moorings." Mobilities 1 (1): 1-22. doi:10.1080/17450100500489189.

Jackson, Emma. 2012. "Fixed in Mobility: Young Homeless People and the City." International Journal of Urban and Regional Research 36 (4): 725-741. doi:10.1111/j.1468-2427.2012.01124.x.

Jensen, Anne. 2011. "Mobility, Space and Power: On the Multiplicities of Seeing Mobility." Mobilities 6 (2): 255-271. doi:10 $.1080 / 17450101.2011 .552903$.

Jocoy, Christine L., and Vincent J. Del Casino. 2010. "Homelessness, Travel Behavior, and the Politics of Transportation Mobilities in Long Beach, California." Environment and Planning A 42 (8): 1943-1963. doi:10.1068/a42341.

Kaika, Maria. 2012. "The Economic Crisis Seen from the Everyday: Europe's Nouveau Poor and the Global Affective Implications of a 'Local' Debt Crisis." City 16 (4): 422-430. doi:10.1080/13604813.2012.696943. 
Kawash, Samira. 1998. "The Homeless Body." Public Culture 10 (2): 319-339.

Lancione, Michele. 2016. "Beyond Homelessness Studies." European Journal of Homelessness 10 (2): $163-176$. doi:10.1215/08992363-10-2-319.

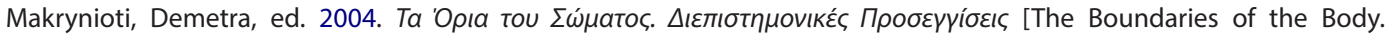
Interdisciplinary Perspectives.] Athens: Nissos.

Manderscheid, Katharina. 2014. "Criticising the Solitary Mobile Subject: Researching Relational Mobilities and Reflecting on Mobile Methods." Mobilities 9 (2): 188-219. doi:10.1080/17450101.2013.830406.

May, Jon. 2000. “Of Nomads and Vagrants: Single Homelessness and Narratives of Home as Place." Environment and Planning D: Society and Space 18 (6): 737-759. doi:10.1068/d203t.

Pile, Steve, and Nigel J. Thrift, eds. 1995. Mapping the Subject. Geographies of Cultural Transformation. London: Routledge.

Sheller, Mimi, and John Urry. 2006. "The New Mobilities Paradigm." Environment and Planning A 38 (2): 207-226. doi:10.1068/ a37268.

Simpson, Paul. 2017. "Spacing the Subject: Thinking Subjectivity after Non-Representational Theory." Geography Compass. 11: e12347. doi:10.1111/gec3.12347.

Smith, Robin James, and Tom Hall. 2016. "Pedestrian Circulations: Urban Ethnography, the Mobilities Paradigm and Outreach Work." Mobilities 11 (4): 498-508. doi:10.1080/17450101.2016.1211819.

Söderström, Ola, Shalini Randeria, Didier Ruedin, Gianni D’Amato, and Francesco Panese. 2013. “Of Mobilities and Moorings: Critical Perspectives." In Critical Mobilities, edited by Ola Söderström, Shalini Randeria, Didier Ruedin, Gianni D’Amato and Francesco Panese, 1-19. London: Routledge.

Somerville, Peter. 1992. "Homelessness and the Meaning of Home: Rooflessness or Rootlessness?" International Journal of Urban and Regional Research 16 (4): 529-539. doi:10.1111/j.1468-2427.1992.tb00194.x.

Wardhaugh, Julia. 1996. "'Homeless in Chinatown': Deviance and Social Control in Cardboard City." Sociology 30 (4): $701-716$. doi:10.1177/0038038596030004005.

Whiteford, Martin. 2010. "Hot Tea, Dry Toast and the Responsibilisation of Homeless People." Social Policy and Society 9 (2): 193-205. doi:10.1017/S1474746409990340.

Wolch, Jennifer R., Afsaneh Rahimian, and Paul Koegel. 1993. "Daily and Periodic Mobility Patterns of the Urban Homeless." The Professional Geographer 45 (2): 159-169. doi:10.1111/j.0033-0124.1993.00159.x.

Wolch, Jennifer R., and Stacy Rowe. 1992. "On the Streets: Mobility Paths of the Urban Homeless." City \& Society 6 (2): 115-140. doi:10.1525/city.1992.6.2.115. 